\title{
Insumos farmacêuticos ativos irregulares no Brasil: análise descritiva de 2011 a 2019
}

\section{Irregular active pharmaceutical inputs in Brazil: descriptive analysis from 2011 to 2019}

\author{
Nubia Naiara Pinto \\ Karina Aparecida Resende (iD \\ Renê Oliveira do Couto* (D)
}

Universidade Federal de São João del-Rei (UFSJ), Divinópolis, MG, Brasil

\footnotetext{
* E-mail: rocouto@ufsj.edu.br
}

\begin{abstract}
RESUMO
Introdução: Os insumos farmacêuticos ativos (IFA) correspondem à parte farmacológica do medicamento e a demanda por esses produtos tem gerado grandes lucros para as indústrias farmoquímicas. Por fazerem parte essencial da cadeia produtiva de medicamentos, os IFA estão sujeitos à fiscalização pela Agência Nacional de Vigilância Sanitária (Anvisa) no Brasil. Objetivo: Realizar análise descritiva dos IFA recolhidos no Brasil entre 2011 e 2019, por meio do website da Anvisa na subseção de "produtos irregulares". Método: Foram obtidos resultados de variáveis denominadas: empresas, motivos, produtos e ações fiscalizadoras. Os resultados foram apresentados como frequências absoluta ou relativa e, dessa forma, traçou-se o perfil descritivo dos insumos irregulares. Resultados: A maioria $(80,0 \%)$ das empresas com IFA recolhidos é de origem internacional, sendo Índia e China os países predominantes. A frequência de inspeções realizadas pela Anvisa nas empresas apresentou forte correlação com a quantidade de insumos apreendidos $(r=0,89)$. As principais motivações de recolhimento de IFA são a deficiência nas Boas Práticas de Fabricação (BPF), ausência de registro e contaminação por nitrosaminas. Dos 95 insumos irregulares avaliados, os antimicrobianos e os anti-hipertensivos (antagonistas de angiontensina II) apresentaram as maiores frequências de recolhimentos. Conclusões: A Anvisa está alinhada aos padrões de qualidade de outras agências regulatórias internacionais e tem cumprido com eficiência seu objetivo institucional de garantir e promover a saúde da população brasileira no que concerne à fiscalização de IFA utilizados na produção de medicamentos.
\end{abstract}

PALAVRAS-CHAVE: Boas Práticas de Fabricação; Gestão da qualidade; Recolhimento de Medicamentos; Vigilância Sanitária

\begin{abstract}
Introduction: The active pharmaceutical ingredients (IFA) correspond to the pharmacological part of the medication and the demand for these products has generated great profits for the pharmacochemical industries. As such products are an essential part of the drug production chain, IFA are subject to inspection by the Brazilian National Health Surveillance Agency (Anvisa) in Brazil. Objective: To perform a descriptive analysis of the IFAs withdrawn from the Brazilian market between 2011 and 2019, through the Anvisa website in the subsection "irregular products". Method: Results were obtained from variables called: manufactures, motivations, products and inspection actions. The results were presented as absolute or relative frequencies, and thus the descriptive profile of the irregular inputs was drawn. Results: The majority (80.0\%) of the companies with collected APIs are of international origin, with India and China being the predominant countries. The frequency of inspections carried out by Anvisa in the companies showcased strong correlation with amount of inputs withdraw from the market $(r=0.89)$. The main motivations for withdraw IFA are the deficiency in Good Manufacturing Practices (GMP), absence of registration and contamination by nitrosamines. Of the 95 irregular inputs evaluated, antimicrobials and antihypertensives (antagonists of angiontensin II) had the greatest frequency of withdrawals. Conclusions: Anvisa is in line with the quality standards of other international regulatory agencies and has effectively fulfilled its institutional aim of guaranteeing and promoting the health of the Brazilian population with regard to the inspection of IFA used in the production of medicines.
\end{abstract}

KEYWORDS: Good Manufacturing Practices; Quality Management; Drug Recalls; Health Surveillance 


\section{INTRODUÇÃO}

Formas farmacêuticas são o resultado da manipulação dos chamados insumos farmacêuticos ativos (IFA) e dos adjuvantes farmacotécnicos, também denominados insumos inertes ou não ativos $^{1,2}$. Os IFA são substâncias químicas que apresentam propriedades farmacológicas com finalidade medicamentosa ${ }^{3}$. 0 consumo em escala mundial destes insumos, em 2016, atingiu o valor de US\$ 144 bilhões $^{4}$. No Brasil, o mercado para IFA tem se demostrado bastante aquecido, de modo que entre 2017 e 2018 observou-se aumento de US\$ 1,4 bilhão nas movimentações financeiras deste setor ${ }^{5}$.

Os IFA representam o início da cadeia produtiva da indústria farmacêutica e, para que sejam comercializados, é necessário que os fabricantes atendam a padrões de qualidade². A Agência Nacional de Vigilância Sanitária (Anvisa) é o órgão responsável pelo controle sanitário e por regulamentar a comercialização de IFA no Brasil ${ }^{5}$. Essa fiscalização deve ser rigorosa para garantir que os IFA utilizados atendam às normas de qualidade, de segurança e de eficácia estabelecidas, por exemplo, detecção de impurezas tóxicas, análise físico-química de teor, caracterização de polimorfos etc. ${ }^{6}$

Para alcançar a qualidade exigida, a Anvisa dispõe aos produtores a ferramenta Boas Práticas de Fabricação (BPF). As BPF são um conjunto de regras direcionadas à orientação quanto à produção de insumos e produtos farmacêuticos com padrões de qualidade adequados $^{7}$. Essas regras devem ser atendidas em todas as etapas da produção para garantir eficácia e segurança aos usuários, bem como credibilidade e competitividade às empresas ${ }^{8}$. Para tanto, os IFA devem ser cadastrados antes de serem fabricados e, em seguida, serem submetidos ao registro e à fiscalização $0^{9,10}$.

Os insumos que apresentarem desvio de qualidade perante a Anvisa, como deficiência nas BPF, devem ser recolhidos do mercado $^{9}$. Ademais, se o insumo inadequado for comercializado em medicamentos, estes ainda devem ser recolhidos do mercado de acordo com a Lei $\mathrm{n}^{\circ} 6.360$, promulgada no dia 23 de setembro de 1976. O recolhimento pode ser voluntário, advindo da empresa fabricante, ou pode ocorrer caso a agência fiscalizadora constate anormalidade do insumo durante a inspeção ${ }^{11}$.

Após o recolhimento do produto, a Anvisa disponibiliza em seu sítio eletrônico, na subseção "produtos irregulares", as informações referentes ao processo de confisco do insumo irregular ${ }^{12}$. Muito embora seja tema de interesse no contexto da promoção da saúde pública em nosso país, não existe até o momento nenhum trabalho científico dedicado a analisar os motivos que levam ao recolhimento de IFA no mercado farmacêutico brasileiro.

Motivado por esta necessidade técnica e visando ampliar o debate sobre a relevância da atuação da Anvisa e de seu papel institucional de promover a proteção da saúde da população, o objetivo deste estudo foi sintetizar e avaliar descritivamente as informações provenientes do recolhimento de IFA no Brasil entre 2011 e 2019.

\section{MÉTODO}

Trata-se de um estudo descritivo realizado em quatro etapas: i) busca de informações; ii) coleta de dados; iii) organização e análise dos dados; e iv) discussão e divulgação dos resultados. As informações sobre IFA recolhidos no Brasil foram coletadas a partir do sítio eletrônico ${ }^{12}$ disponibilizado gratuitamente pela Anvisa, da seguinte forma: no campo de "Atuação", foi selecionado o item "Fiscalização e Monitoramento", na sequência o item "Consultas e Serviços" e o subitem "Produtos irregulares".

Foram selecionadas e incluídas na pesquisa todas as ações de fiscalização (ou seja, apreensão e inutilização, recolhimento, interdição, suspensão, proibição e alterações) de insumos farmacêuticos falsificados e irregulares notificados entre $1^{\circ}$ de janeiro de 2011 a 31 de dezembro de 2019. Foram excluídos da pesquisa alimentos, saneantes, medicamentos, cosméticos e produtos para saúde presentes no sítio eletrônico.

Foram coletados os dados referentes a: número da resolução específica; data de publicação; produto; lote; empresa; data de fabricação; validade; ação de fiscalização; observação e motivação. Então, todos os dados foram organizados, codificados e duplamente checados em planilha eletrônica. As variáveis empresa, motivo, produto e ação fiscalizadora foram analisadas como descrito a seguir:

I. Empresas: a primeira etapa determinou o total de empresas que apresentou IFA irregulares. Posteriormente, avaliou-se a frequência que cada empresa foi citada no decorrer de 9 anos (2011-2019). Posteriormente, somou-se o número de empresas que são de origem internacionais e nacional, de forma a identificar quais os países apresentam empresas com IFA recolhidos.

II. Motivo: foi determinado o total de motivos apresentados como justificativa de classificar os insumos como inadequados. Consecutivamente, cada motivo foi analisado quanto ao número de ocorrências em que foi mencionado, destacando os principais motivos passíveis de causar o recolhimento do material.

III. Produto: foram contabilizados quantos tipos de insumos, foram confiscados e aqueles descritos como: "todos insumos". Em seguida, avaliou-se a ocorrência que cada categoria de insumo foi mencionada, obtendo assim os tipos de IFA mais predominantes. Por fim, elaborou-se o panorama da quantidade e tipos de insumos citados por ano.

IV. Ação fiscalizadora: computou-se o total de ações de fiscalização realizadas no período analisado e, logo após, evidenciou-se quais ações foram mais comumente aplicadas. Entre as ações, a revogação foi analisada de forma individualizada, visando determinar quantas foram classificadas como satisfatórias e insatisfatórias. 
Para o resumo, a análise e a interpretação dos dados obtidos, estes foram descritos na forma de frequência absoluta e relativa (\%) e apresentados em tabelas e gráficos de pizza e barras verticais. Ainda, para determinação da interdependência entre a frequência anual de inspeções e a quantidade de produtos recoIhidos, análises de correlação e regressão linear foram conduzidas pela técnica dos mínimos quadrados, considerando intervalo de confiança de $95 \%$. O resultado foi expresso por meio do coeficiente de correlação de Pearson (r).

Em seguida, procedeu-se à discussão dos resultados perante as resoluções nacionais e estudos encontrados na literatura. 0 percurso metodológico dessa pesquisa foi respaldado pela Lei Nacional de Acesso à Informação (Lei $\mathrm{n}^{\circ} 12.527$, de 18 de dezembro de 2011) ${ }^{13}$ e pela Resolução $n^{\circ} 510$, de 7 de abril de 2016, do Conselho Nacional de Saúde ${ }^{14}$.

\section{RESULTADOS E DISCUSSÃO}

\section{Empresas}

A Tabela 1 apresenta o total de empresas contabilizadas e identificadas nos registros de fiscalização da Anvisa entre 2011 e 2019. Destas, 24 foram citadas uma vez, correspondendo a 33,8\% do total. Portanto, $66,2 \%$ (47) das empresas foram reincidentes, ou seja, apresentaram mais de uma notificação. Isso evidencia a ocorrência frequente de irregularidades e, por consequência, fragilidades sistemáticas na política de qualidade destes fabricantes.

Estudos anteriores a respeito de IFA irregulares são escassos, principalmente no que tange as variáveis analisadas nesse estudo. A elevada margem de identificação reitera a eficiência no recolhimento de informações durante as inspeções e transparência da Anvisa com o público brasileiro. Conforme mostrado na Tabela $1 \mathrm{e}$ levando em consideração o período de análise do estudo, apenas uma vez todas as empresas produtoras de somatomedina C (IGF-I) foram notificadas em conjunto. A literatura mostra que em 2015, a somatomedina C (IGF-I) foi retirada do mercado, dessa forma a Anvisa solicitou que todas as empresas suspendessem a produção desse IFA. Essa medida se tornou necessária já que esse insumo não apresentou avaliação da eficácia terapêutica e, consequentemente, a aprovação da Anvisa para comercialização ${ }^{15}$.

Sabe-se que, com a implantação da RDC $n^{\circ} 30$, de 15 de maio de $2008^{16}$, todos os IFA devem ser cadastrados para permitir a

Tabela 1. Valores absolutos e relativos das empresas identificadas e não identificadas pela Agência Nacional de Vigilância Sanitária entre 2011 e 2019.

\begin{tabular}{lcc}
\hline Empresas & $\begin{array}{c}\text { Frequência } \\
\text { absoluta }\end{array}$ & $\begin{array}{c}\text { Frequência } \\
\text { relativa (\%) }\end{array}$ \\
\hline Não descrita no portal da Anvisa* & 5 & 6,5 \\
Todas as empresas** $^{* *}$ & 1 & 1,3 \\
Identificadas & 71 & 92,2 \\
\hline Total & 77 & 100,0
\end{tabular}

Fonte: Portal eletrônico da Anvisa, 2020.

* 0 termo se refere àquelas descritas pela Anvisa como "desconhecida" ou "não se aplica".

** Todas as empresas fabricantes da somatomedina C (IGF-I) tiveram produção suspensa. identificação dos fabricantes e a rastreabilidade dos insumos comercializados no Brasil. Algumas empresas podem não ter sido cadastradas e, por isso, não foi possível divulgar a identificação do fabricante no portal da Anvisa (Tabela 1).

Entre as empresas reconhecidas, 57 são de origem estrangeira e 14 são nacionais. Os países que apresentaram maior prevalência de empresas advertidas foram: Índia (31), China (19) e Brasil (14). Na Figura 1 estão apresentadas as frequências relativas das nacionalidades destas empresas. Estudos demonstraram que ao longo da última década, $90 \%$ dos IFA utilizados no Brasil foram provenientes de importações, sendo a maioria de origem asiática ${ }^{4,17}$. A predominância desses países asiáticos pode ser atribuída à legislação trabalhista menos rigorosa, além de medidas de incentivo à exportação e, muitas vezes, por menor adequabilidade às BPF e por oferecerem os produtos a preços reduzidos ${ }^{18,19}$.

Em 2012, a agência reguladora estadunidense Food and Drug Administration (FDA) intensificou o rigor das inspeções nos produtores de IFA ${ }^{18,19}$. A Anvisa, alinhada à FDA, também implantou maior rigor ao setor farmacoquímico 4 . Ainda em 2012, inspecionou 17 empresas chinesas, das quais oito $(47,0 \%)$ foram reprovadas por desqualificação sanitária ${ }^{18}$.

A Figura 2 mostra os estados brasileiros que apresentaram empresas advertidas, evidenciando destaque para São Paulo com seis empresas. Essa dominância está relacionada à concentração do polo farmoquímico brasileiro na região Sudeste, com cerca de $81,0 \%$ das indústrias produtoras de insumos ${ }^{20}$. A cidade de Anápolis, localizada no estado de Goiás (região Centro-Oeste) constitui o segundo maior polo farmoquímico do Brasil ${ }^{21}$.

\section{Recolhimento de insumos ao longo dos anos}

No período analisado foram recolhidos 95 insumos. Observa-se na Figura 3 uma redução gradual de insumos irregulares entre os anos 2011 a 2014. 0 ano 2019 foi o que apresentou maior número de recolhimento.

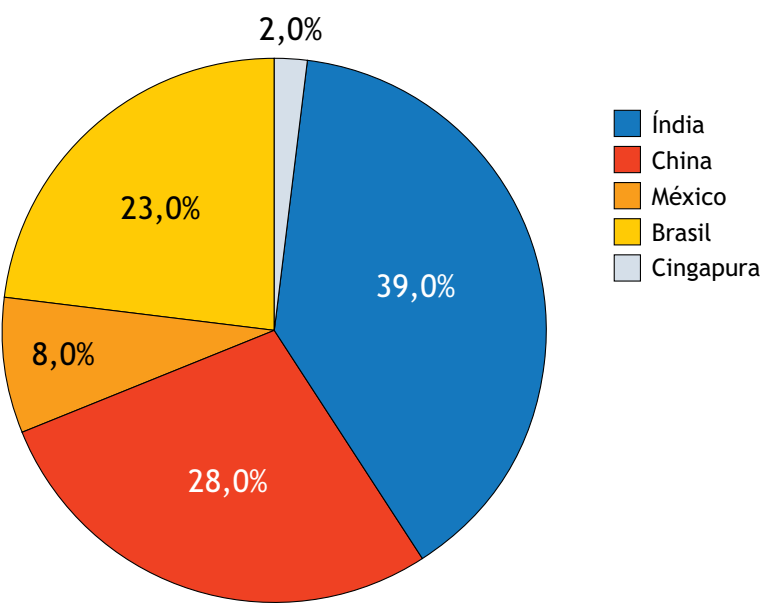

Fonte: Portal eletrônico da Anvisa, 2020.

Figura 1. Frequência relativa de empresas com insumos farmacêuticos ativos recolhidos pela Agência Nacional de Vigilância Sanitária entre 2011 e 2019 em função da nacionalidade do fabricante. 


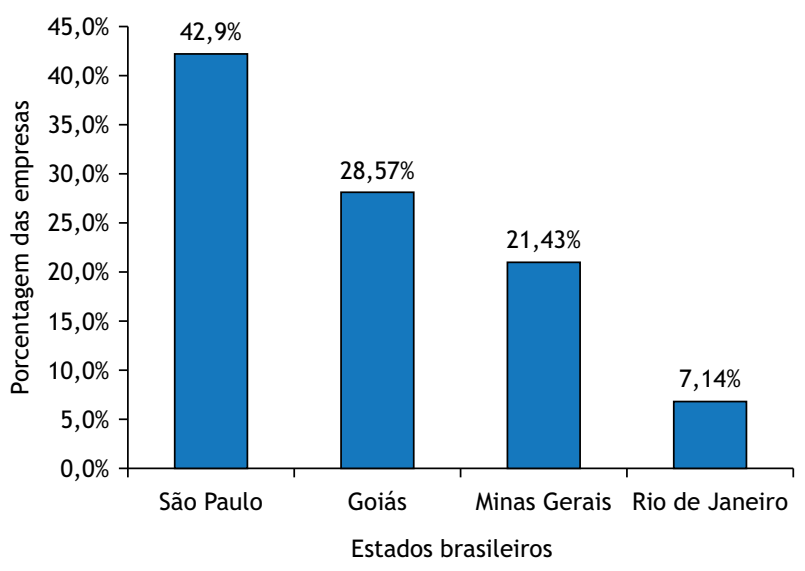

Fonte: Portal eletrônico da Anvisa, 2020.

Figura 2. Frequência relativa de empresas com insumos farmacêuticos ativos recolhidos pela Agência Nacional de Vigilância Sanitária entre 2011 e 2019 em função do estado do fabricante.

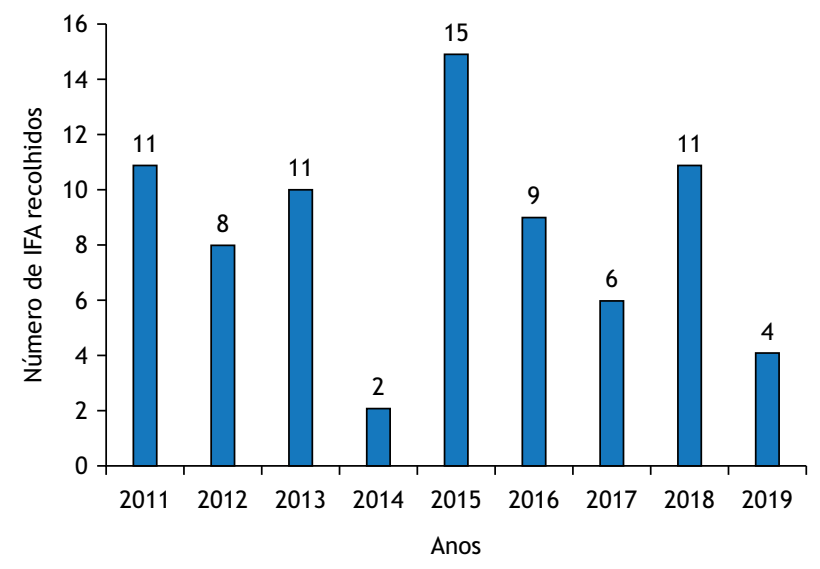

Fonte: Portal eletrônico da Anvisa, 2020.

Figura 3. Frequência absoluta dos recolhimentos de insumos farmacêuticos ativos entre 2011 a 2019 no Brasil.

De acordo com a Figura 3, o ano de 2014 apresentou queda de $80,0 \%$ na notificação de IFA em relação ao ano anterior. Embora a exportação no país não seja muito significativa, o setor farmoquímico em 2014 arrecadou US\$ 561,4 milhões, valor inferior se comparado ao de 2013, quando o lucro foi de US\$ 642,6 milhões $^{5}$. Isto representa uma queda de $12,7 \%$, que pode ser atribuída a menor produção de insumos adequados ou não ao consumo.

Em 2015 foram recolhidos 12 IFA a mais do que no ano anterior. Esse acréscimo pode estar relacionado ao maior número de inspeções em indústrias farmoquímicas, o qual permitiu detectar uma maior quantidade de IFA irregulares. Nos relatórios disponibilizados pela Anvisa observou-se que, em 2015, 63 empresas foram inspecionadas, ao passo que em 2014 foram 34 empresas $^{22,23}$.

O aumento de 2015 também pode ser associado à normativa Instrução Normativa (IN) $n^{\circ} 3$, de 3 de junho de $2013^{24}$, que dispõe o ano de 2014 como o prazo final para efetuar a petição do registro obrigatório dos novos insumos. Algumas empresas podem não ter se adequado à legislação em tempo hábil, o que resultou no recolhimento de insumos que foram fabricados em desacordo com a legislação no ano de 2015. Outro fator que pode explicar tal volume de recolhimento é o não atendimento à $\operatorname{RDC} n^{\circ} 69$, de 8 de dezembro de $2014^{7}$, que dispõe sobre o regulamento de BPF específica para IFA.

Nos anos de 2016 e 2017, as importações de insumos farmacêuticos e medicamentos reduziram-se para US\$ 8,4 bilhões e, em 2018 , esse valor atingiu US\$ 9,8 bilhões $^{5}$. 0 aumento de importações sugere que maiores quantidades de insumos foram fabricadas por nossos parceiros comerciais, o que pode estar associado à produção com desvios de qualidade pelos motivos já relacionados, e culminou no aumento de IFA recolhidos em 2018 (Figura 3).

Foi estimado um crescimento de $10 \%$ no mercado farmacêutico global em 2019, sendo considerado o ano de maior crescimento em relação aos últimos cinco anos ${ }^{25}$. Paralelamente a este cenário econômico favorável, observou-se um aumento no número de inspeções da Anvisa em empresas no setor farmoquímico. Em 2018 e 2019 foram constatadas, respectivamente, 52 e 61 inspeções ${ }^{26,27}$. Além disso, almejando aumentar o rigor e eficácia de suas ações, por meio da consulta pública (CP) n $n^{\circ} 688$, de 12 de agosto de 2019, a Anvisa tem discutido novos critérios de certificação de BPF para estabelecimentos internacionais fabricantes de IFA ${ }^{28}$. Em conjunto, estes fatores podem ser a causa do aumento expressivo do recolhimento de IFA em 2019.

Considerando os resultados obtidos para os anos 2014, 2015, 2018 e 2019, foi determinada uma forte correlação linear $(r=0,89)$ entre o número de inspeções realizados pela Anvisa e o número de produtos recolhidos do mercado, ou seja, quanto maior o número de empresas inspecionadas, maior o número de produtos irregulares identificados.

\section{Perfil dos insumos irregulares}

As classes terapêuticas dos IFA recolhidos pela Anvisa entre 2011 e 2019 no Brasil são apresentadas na Tabela 2. Foram identificados $81(85,3 \%)$ insumos e $14(14,7 \%)$ não foram identificados pelos seus respectivos nomes. Nesses casos, a Anvisa descreveu os IFA não identificados como "todos os insumos". Dos insumos antimicrobianos foram contabilizados 17 cefalosporinas, três penicilinas, quatro licosaminas, uma quinolona e nove rifampicinas. Os anti-hipertensivos recolhidos são representados somente pela classe dos antagonistas do receptor de angiotensina, sendo 11 valsartanas, cinco losartanas e uma ibersatana. Dentre os anticonvulsivantes foram citadas quatro vezes a fenitoína, uma vez a carbamazepina. Os antagonistas do receptor $\mathrm{H}_{2}$ correspondera somente à ranitidina. Os antivirais corresponderam a duas lamivudinas e dois aciclovir, totalizando quatro insumos.

A alta ocorrência de recolhimento de antimicrobianos, além da demanda clínica, também pode ser atribuída à IN $n^{\circ} 3 / 2013^{24}$. Essa normativa declara o registro obrigatório de mais dez insumos, sendo a maioria pertencente à classe dos antimicrobianos e com prazo máximo de petição até 2014. Outro fator a ser considerado é a IN nº 35, 21 de agosto de $2019^{29}$, relacionada a BPF de 
Tabela 2. Principais classes terapêuticas de insumos farmacêuticos ativos recolhidos pela Agência Nacional de Vigilância Sanitária entre 2011 a 2019 no Brasil.

\begin{tabular}{lcc}
\hline Classe terapêutica & $\begin{array}{c}\text { Frequência } \\
\text { absoluta }\end{array}$ & $\begin{array}{c}\text { Frequência } \\
\text { relativa (\%) }\end{array}$ \\
\hline Antimicrobianos & 34 & 35,8 \\
Anti-hipertensivos & 17 & 17,9 \\
Anticonvulsivantes & 5 & 5,3 \\
Antagonistas do receptor $\mathrm{H}_{2}$ & 5 & 5,3 \\
Antivirais & 4 & 4,2 \\
Outras classes & 30 & 31,5 \\
\hline Total & 95 & 100,0 \\
\hline
\end{tabular}

Fonte: Portal eletrônico da Anvisa, 2020.

medicamentos estéreis, uma vez que seis cefalosporinas foram recolhidas por estarem em desacordo com essa normativa.

Os anti-hipertensivos foram a segunda classe mais citada. Sabe-se que a transição demográfica provoca crescimento de doenças cardiovasculares, por isso, a demanda por IFA anti-hipertensivos tem aumentado consideravelmente ${ }^{30}$. A venda dos medicamentos para doenças cardiovasculares liderou o mercado no Brasil em 2016, quando o faturamento das empresas farmacêuticas com a venda destes produtos atingiu R\$ 5,7 bilhões ${ }^{31}$.

Agências fiscalizadoras como a FDA e a European Directorate for the Quality of Medicines \& HealthCare (EDQM) têm recolhido do mercado anti-hipertensivos por constatar a presença de nitrosaminas carcinogênicas, principalmente em amostras de valsartana ${ }^{32}$. Diante da grande ocorrência de contaminação nos antagonistas de receptor de angiotensina II, a Anvisa decretou a RDC $n^{\circ} 283$, de 17 de maio de $2019^{33}$ para assegurar o controle de nitrosaminas em insumos comercializados no Brasil.

Em 2019, a contaminação por nitrosaminas foi significativa no insumo ranitidina. A Anvisa, ao acompanhar a contaminação de novos insumos, tem recomendado por nota informativa que todos os fabricantes revisem a rota sintética dos IFA e realizem testes que detectem a presença desse tipo de impureza ${ }^{34}$.

Os anticonvulsivantes são utilizados para comorbidades psiquiátricas, principalmente as epilepsias. Estima-se que as epilepsias atinjam entre 0,5 a $1,0 \%$ da população ${ }^{35}$. Ainda que utilizados em menor escala do que as classes terapêuticas citadas anteriormente, estes fármacos são fabricados regularmente, devido ao uso contínuo pelo consumidor. As causas mais comuns que culminaram nos recolhimentos de anticonvulsivantes foram a ausência de Certificado de Boas Práticas de Fabricação (CBPF) por parte dos fabricantes ou irregularidade nas $\mathrm{BPF}^{19}$.

\section{Motivos de recolhimento}

Os principais motivos de recolhimento de IFA pela Anvisa de 2011 a 2019 no Brasil são apresentados na Tabela 3. Dos 68 motivos encontrados, $60(88,2 \%)$ se repetiram e oito $(11,3 \%)$ foram citados só uma vez. O não cumprimento das BPF é o principal motivo para o recolhimento de IFA, seguido da identificação de impurezas potencialmente tóxicas. Um estudo analisou 255 relatórios de inspeção da Anvisa de empresas produtoras de medicamentos entre 2015 e 2016. Destes, 12,5\% foram considerados insatisfatórios por inconformidade com as $\mathrm{BPF}^{36}$. Esses precedentes corroboram com os resultados aqui apresentados.

Durante o processo de inspeção, os estudos de estabilidade deficientes, os controles de qualidades dos IFA inadequados e os relatórios de produções insatisfatórios são as principais causas para inviabilizar a admissão do CBPF. Normalmente, quando a Anvisa encontra deficiências consideradas de menor criticidade e passíveis de resolução, como desvios leves nas BPF, a empresa ganha o prazo de 120 dias para reparar as irregularidades. Entretanto, se for encontrado um total de seis deficiências consideradas graves, o CBPF é recusado de imediato ${ }^{36}$.

0 registro permite o maior rastreamento do insumo e controle sanitário, por isso é obrigatório registrar os IFA junto à Anvisa9,37. A implantação dos registros iniciou-se com a IN $n^{\circ} 15$, de 26 de maio de $2009^{38}$, e, posteriormente, com a IN n ${ }^{\circ} 3 / 2013^{24}$, e ambas definem prazos para registrar insumos prioritários. Há relatos de que $28,6 \%$ das indústrias farmacêuticas inspecionadas apresentam alguma não conformidade com a documentação, incluindo, principalmente, o registro ${ }^{36}$.

A Anvisa adota elevado rigor quanto às práticas regulatórias para os produtos farmacêuticos, dentre as quais destaca-se, o registro de IFA, o controle de qualidade dos insumos, estudo de estabilidade, detecção de impurezas e relatório completo de produção ${ }^{24,36}$. Além disso, a agência exige o Estudo de Degradação Forçada (EDF) dos IFA, fundamental para a concessão do registro do produto final, ou seja, o medicamento. 0 objetivo do EDF é minimizar o risco sanitário por contribuir na garantia da qualidade, da segurança e da eficácia dos produtos ${ }^{39,40,41}$. Assim, a literatura mostra que a Anvisa notificou, durante inspeções, maior número de resultados insatisfatórios para o mercado de medicamentos do que outras autoridades regulatórias, como a Agência Europeia de Medicamentos (EMA) ${ }^{36}$.

As nitrosaminas são sintetizadas a partir do ácido nitroso, originando aminas secundárias e terciárias, devido à variedade de aminas

Tabela 3. Principais motivos para o recolhimento de insumos farmacêuticos ativos com qualidade considerada insatisfatória no Brasil entre 2011 e 2019 de acordo com a Agência Nacional de Vigilância Sanitária.

\begin{tabular}{lcc}
\hline Motivos & $\begin{array}{c}\text { Frequência } \\
\text { absoluta }\end{array}$ & $\begin{array}{c}\text { Frequência } \\
\text { relativa (\%) }\end{array}$ \\
\hline $\begin{array}{l}\text { Não atendimento às BPF } \\
\begin{array}{l}\text { Não atendimento às exigências } \\
\text { regulamentares da Anvisa ou não } \\
\text { apresenta registro }\end{array}\end{array}$ & 19 & 27,9 \\
$\begin{array}{l}\text { Suspensão do certificado de } \\
\text { adequabilidade pela European Directorate } \\
\text { for the Quality of Medicines \& HealthCare }\end{array}$ & 10 & 14,7 \\
$\begin{array}{l}\text { Impurezas - nitrosaminas } \\
\text { Outros motivos }\end{array}$ & 13 & 14,7 \\
\hline Total & 16 & 19,1 \\
\hline
\end{tabular}

Fonte: Portal eletrônico da Anvisa, 2020.

BPF: Boas Práticas de Fabricação; Anvisa: Agência Nacional de Vigilância Sanitária. 
contidas nas matérias-primas. A presença desse agente é comum de ocorrer após períodos extensos de armazenamento, levando à contaminação do insumo ${ }^{42}$. Nos registros avaliados, foram relatados dez casos de identificações de $\mathrm{N}$-nitrosodimetilamina (NDMA) e dois casos de $\mathrm{N}$-nitrosodietilamina (NDEA), as quais apresentam potenciais carcinogênicos quando consumidas a longo prazo.

Estima-se que uma em cada 6 mil pessoas que fazem uso diário e contínuo de medicamento contaminado com nitrosamina por cinco anos poderá desenvolver câncer, principalmente hepático ${ }^{43}$. Nesse contexto, a Anvisa em conjunto com a FDA e EMA têm instruído a realização de testes de quantificação, além de recomendar a reavaliação das rotas sintéticas de todos os insumos que pertencem a produção da indústria ${ }^{34}$.

\section{Ações fiscalizadoras da Anvisa}

Verificou-se o total de 187 ações fiscalizadoras distribuídas em 17 categorias. Os anos que apresentaram maiores números de ações foram o de 2019 e 2018, seguidos por 2013, conforme demonstra a Figura 4.

As ações de fiscalizações que apresentaram maiores frequências ao longo de nove anos foram: a suspensão de importação e a suspensão de uso. Já uma das que apresentou menor ocorrência foi a suspensão de exportação (Tabela 4).

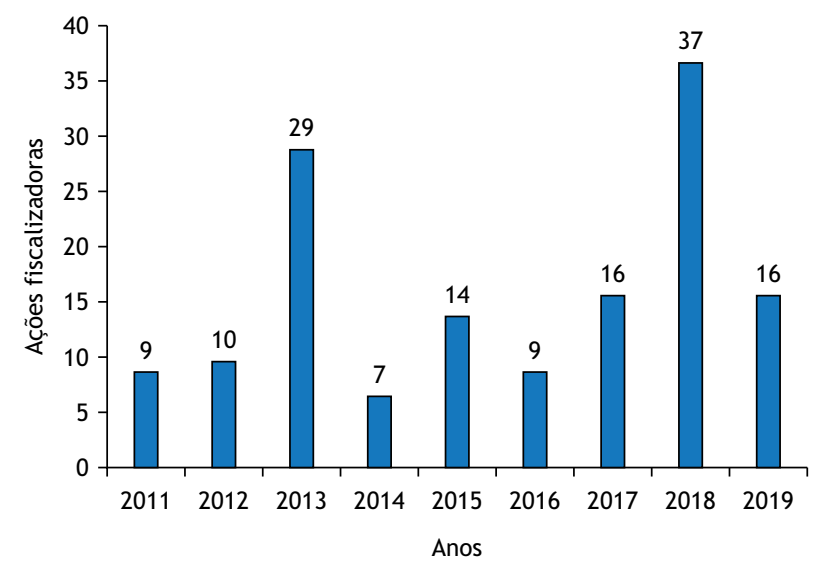

Fonte: Portal eletrônico da Anvisa, 2020.

Figura 4. Frequência absoluta de ações fiscalizadoras da Agência Nacional de Vigilância Sanitária entre 2011 a 2019 no Brasil.

Tabela 4. Frequências absoluta e relativa das principais ações fiscalizadoras para insumos farmacêuticos ativos realizadas pela Agência Nacional de Vigilância Sanitária entre 2011 a 2019 no Brasil.

\begin{tabular}{lcc}
\hline Ação fiscalizadora & $\begin{array}{c}\text { Frequência } \\
\text { absoluta }\end{array}$ & $\begin{array}{c}\text { Frequência } \\
\text { relativa (\%) }\end{array}$ \\
\hline Suspensão de importação & 50 & 26,7 \\
Suspensão de uso & 35 & 18,7 \\
Suspensão de distribuição & 33 & 17,7 \\
Suspensão de exportação & 1 & 0,5 \\
Outras ações & 68 & 36,4 \\
\hline Total & 187 & 100,0 \\
\hline
\end{tabular}

Fonte: Portal eletrônico da Anvisa, 2020.
As ações de fiscalização são medidas sanitárias que visam prevenir a população de usar fármacos que trazem riscos à saúde, assegurado pela Lei $\mathrm{N}^{\circ} 6.437$, de 20 de agosto de $1977^{44}$. As empresas com regulamentações incoerentes tornam-se passíveis as aplicações das ações fiscais. No geral, são ações preventivas classificadas como suspensão, as quais são adotadas até a empresa regularizar as pendências. No entanto, nos casos de irregularidades graves, como produtos ilegais, a Anvisa pode aplicar ações corretivas que abrangem apreensão e inutilização, proibição de: distribuição, comércio, uso ou divulgação ${ }^{45}$.

Dentre as ações, a suspensão de importação é a mais recorrente (26,5\%), o que é compreensível, uma vez que a maioria dos IFA utilizados no Brasil é de origem extrangeira ${ }^{4}$. Em contrapartida, a suspensão da exportação ocorreu apenas uma vez $(0,7 \%)$, a qual pode ser explicada pela baixa produção de farmoquímicos no Brasil.

No geral, observou-se que o ano que apresentou maior quantidade de empresas advertidas foi também o ano com maior número de ações fiscais citadas. Em 2019, 16 empresas foram notificadas. Em 2018, foram 14 empresas e 12 empresas em 2013. 0 ano de 2019, apesar de apresentar duas empresas a mais do que 2018, apresentou o dobro de ações, o que pode representar maior rigor. A fabricação de IFA tem atraído cada vez mais atenção das agências regulatórias, sendo objeto de discussão em consultas públicas sobre as BPF e a qualificação de forncedor ${ }^{28,46}$.

Foram identificadas 11 revogações, sendo que oito delas resultaram em satisfatórias, por apresentarem adequação correta as exigências da Anvisa e, em duas, não foram encontradas informações a respeito das suas respectivas classificações, conforme apresentado na Figura 5. Em 2016, foi verificado o maior número de revogações, ou seja, quatro (36,0\%). Em 2014 e 2019, não foram verificadas revogações. Em contrapartida, foi observada uma revogação para cada ano restante.

A revogação é um processo que permite anular a ação fiscal desde que a empresa retifique as inconformidades notificadas pela Anvisa. Ainda que a maioria das revogações tenha sido satisfatória, apenas 11

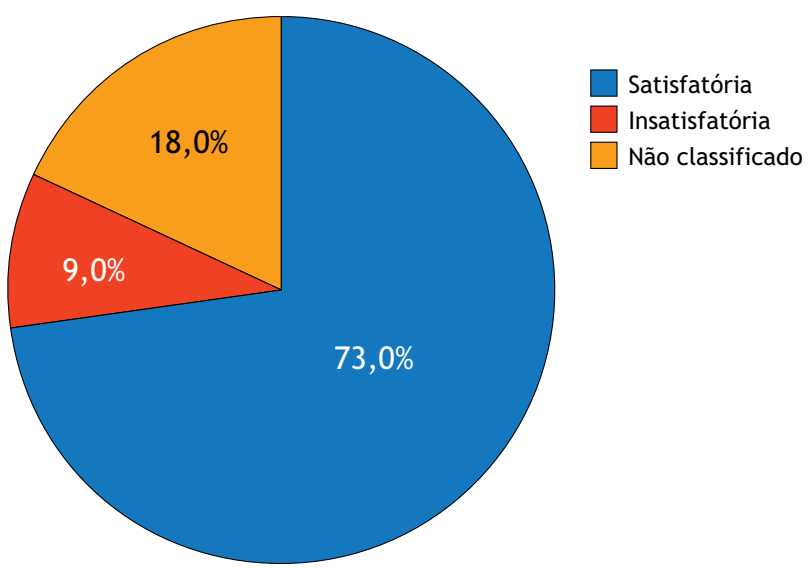

Fonte: Portal eletrônico da Anvisa, 2020.

Figura 5. Frequência relativa das revogações relacionadas ao recolhimento de insumos farmacêuticos ativos apresentadas pela Agência Nacional de Vigilância Sanitária nos anos de 2011 a 2019, no Brasil. 
$(14,3 \%)$ do total das 77 empresas advertidas passaram pelo processo de revogação. Os dados sugerem que a maioria das empresas não passou por nova inspeção para verificar a readequação à regulamentação.

O ano 2016 foi destaque em quantidade de ações de revogação, cerca de $36,0 \%$. Entretanto, não foi encontrado nenhum embasamento técnico/científico que justifique o predomínio nesse ano. Por outro lado, a ausência de revogação em 2014 pode ser associada à baixa quantidade de empresas notificadas, ou seja, três. Já no ano de 2019, apesar de ter havido o maior número de empresas advertidas, nenhuma delas foram citadas para a ação de revogação.

O presente estudo apresenta limitações relacionadas à ausência de informações ou de estudos comparativos referentes a insumos, ocorrendo um predomínio de estudos sobre os medicamentos. Os dados mostram que a predominância de IFA irregulares ocorre por inconformidades nas BPF. Entretanto, na maioria das ocorrências, a Anvisa não aponta qual(is) item(ns) específico(s) da legislação vigente relativa às BPF não foram cumpridos no ato das inspeções. Para preencher esta lacuna, seria oportuna a disponibilização integral do relatório de inspeção na plataforma digital da Anvisa, visto que estas informações são relevantes e de interesse público. Embora as ações fiscalizadoras sejam citadas, há insuficiência de informações a respeito dos parâmetros utilizados para aplicar determinadas ações, o que limitou a discussão.

\section{CONCLUSÕES}

A maior parte dos insumos presentes no Brasil foi de origem estrangeira, uma vez que a importação no setor farmoquímico é mais evidente e ocorre uma predominância dos fabricantes localizados na China e na índia. A maioria das empresas advertidas nessa análise foram identificadas, o que demonstra transparência e eficiência por parte da Anvisa.

A frequência de inspeções foi fundamental para detectar irregularidades na produção, já que o maior número de inspeções influenciou a quantidade de IFA irregulares encontrados. As classes terapêuticas com maior predomínio de insumos recolhidos foram os antimicrobianos e anti-hipertensivos.

O principal motivo para o recolhimento de IFA é a deficiência nas BPF. Entretanto, a Anvisa não publicou quais itens específicos da legislação vigente as empresas deixaram de cumprir. Por outro lado, a Anvisa apresenta credibilidade ao elaborar normas regulatórias, as quais são bem ilustradas. Além disso, as ações de fiscalização adotadas estão alinhadas aos padrões de agências internacionais como FDA e EMA.

E notório que a Anvisa tem se mobilizado para atingir excelência no controle sanitário nacional, com destaque para as atualizações de resoluções, condução de debates em consultas públicas e aumento da frequência e rigor das inspeções nas indústrias farmoquímicas.

Em função de seu ineditismo, espera-se que esse estudo contribua para publicações futuras e possa servir como material didático na seara da gestão da qualidade aplicada à produção de IFA. Ademais, é digno de nota que trabalhos acadêmicos como este, contemplando ensino, pesquisa e extensão, contribuem para a formação de profissionais farmacêuticos com visão crítica e multidisciplinar, bem como para o empoderamento da população quanto à qualidade dos IFA utilizados na fabricação de medicamentos no Brasil.

\section{REFERÊNCIAS}

1. Silva CCP. Caracterização de estado sólido de insumos farmacêuticos ativos: clorpropamida, nevirapina e dietilcarbamazepina [dissertação]. São Carlos: Universidade de São Paulo; 2010.

2. Agência Nacional de Vigilância Sanitária - Anvisa. Insumos farmacêuticos. Rev Saude Publica. 2006;40(2):359-60. https://doi.org/10.1590/S0034-89102006000200027

3. Pontes AT, Xavier LS, Futuro DO, Peixoto JAS. Uma reflexão da qualidade dos insumos farmacêuticos presentes no mercado brasileiro e seu impacto na produção de medicamentos. In: Anais do $29^{\circ}$ Encontro Nacional de Engenharia de Produção; Salvador, Brasil. Rio de Janeiro: Associação Brasileira de Engenharia de Produção; 2009[acesso 16 fev 2019]. Disponível em: http://webcache. googleusercontent.com/search?q=cache:xJxqF LmC4J:www.abepro.org.br/biblioteca/enegep2009_tn_ stp_091_621_13065.pdf +\&cd=1\&hl=pt-BR\&ct=clnk\&gl=br

4. Mitidieri TL, Pimentel VP, Braga CA, Pieroni JP. Há espaços competitivos para a indústria farmoquímica brasileira? Reflexões e propostas para políticas públicas. BNDES Setor 41. 16 abr 2015[acesso 3 fev 2019]. Disponível em: https://web. bndes.gov.br/bib/jspui/bitstream/1408/4286/1/BS\%2041\%20
H\%c3\%a1\%20espa\%c3\%a7os\%20competitivos\%20para\%20a\%20 ind\%c3\%bastria\%20farmoqu\%c3\%admica_P.pdf

5. Associação Brasileira da Indústria de Insumo Farmacêutico - Abiquif. Cadeia produtiva farmoquímicafarmacêutica: retomada das exportações perde fôlego. São Paulo: Associação Brasileira da Indústria de Insumo Farmacêutico; 2019[acesso 15 abr 2019]. Disponível em: http://abiquifi.org.br/mercado

6. Agência Nacional de Vigilância Sanitária - Anvisa. Resolução RDC N 359, de 27 de março de 2020. Institui o dossiê de insumo farmacêutico ativo (DIFA) e a carta de adequação de dossiê de insumo farmacêutico ativo (Cadifa). Diário Oficial União. 1 abr 2020.

7. Agência Nacional de Vigilância Sanitária - Anvisa. Resolução RDC N 69, de 8 de dezembro de 2014. Dispõe sobre as boas práticas de fabricação de insumos farmacêuticos ativos. Diário Oficial União. 9 ago 2014.

8. Abdellah A, Noordin MI, Ismail WAW. Importance and globalization status of good manufacturing practice (GMP) requirements for pharmaceutical excipients. Saud Phar J. 2015;23(1):9-13. https://doi.org/10.1016/j.jsps.2013.06.003 
9. Agência Nacional de Vigilância Sanitária - Anvisa. Resolução RDC $N^{\circ}$ 57, de 17 de novembro de 2009. Dispõe sobre o registro de insumos farmacêuticos ativos (IFA) e dá outras providências. Diário Oficial União. 18 nov 2009.

10. Agência Nacional de Vigilância Sanitária - Anvisa. Resolução RDC № 45, de 9 de agosto de 2012. Dispõe sobre a realização de estudos de estabilidade de insumos farmacêuticos ativos. Diário Oficial União. 10 ago 2012.

11. Macedo I, Reis S, Garrafa V. Vigilância sanitária: recolhimento de medicamentos na legislação brasileira. Rev Bio. 2010;18(3):623-35.

12. Agência Nacional de Vigilância Sanitária - Anvisa. Produtos irregulares. Brasília: Agência Nacional de Vigilância Sanitária; 2020[acesso 20 jun 2020]. Disponível em: http://portal.anvisa.gov.br/produtos-irregulares\#/

13. Brasil. Lei $N^{\circ} 12.527$, de 18 de novembro de 2011. Regula o acesso a informações previsto no inciso 33 do artigo 5 , no inciso 2 do parágrafo 3 do artigo 37 e no parágrafo 2 do artigo 216 da constituição federal; altera a lei no 8.112, de 11 de dezembro de 1990; revoga a lei no 11.111 , de 5 de maio de 2005, e dispositivos da lei no 8.159 , de 8 de janeiro de 1991; e dá outras providências. Diário Oficial União. 19 nov 2011.

14. Ministério da Saúde (BR). Resolução $N^{\circ} 510$, de 7 de abril de 2016. Dispõe sobre as normas aplicáveis a pesquisas em ciências humanas e sociais cujos procedimentos metodológicos envolvam a utilização de dados diretamente obtidos com os participantes ou de informações identificáveis ou que possam acarretar riscos maiores do que os existentes na vida cotidiana, na forma definida nesta resolução. Diário Oficial União. 24 maio 2016.

15. Ascom. Anvisa suspende a manipulação do insumo somatomedina C. Anvisa Medicamentos. 20 jan 2016[acesso 15 jun 2020]. Disponível em: http://portal.anvisa.gov. br/noticias/-/asset_publisher/FXrpx9qY7FbU/content/ anvisa-suspende-a-manipulacao-do-insumo-somatomed inac / 219201?inheritRedirect=false\&redirect $=$ http $\% 3 A \% 2$ F\%2Fportal.anvisa.gov.br\%2Fnoticias\%3Fp_p_id\%3D101_ INSTANCE_FXrpx9qY7FbU\%26p_p_lifecycle\%3D0\%26p_p_ state\%3Dnormal\%26p_p_mode\%3Dview\%26p_p_col_ id\%3Dcolumn-2\%26p_p_col_count\%3D1\%26p_r_p_564233524_ tag\%3Dsomatomedina\%2B

16. Agência Nacional de Vigilância Sanitária - Anvisa. Resolução RDC $N^{\circ} 30$, de 15 de maio de 2008. Dispõe sobre a obrigatoriedade de todas as empresas estabelecidas no país, que exerçam as atividades de fabricar, importar, exportar, fracionar, armazenar, expedir e distribuir insumos farmacêuticos ativos, cadastrarem junto à Anvisa todos os insumos farmacêuticos ativos com os quais trabalham. Diário Oficial União. 16 maio 2008.

17. Rodrigues PHA, Costa RDF, Kiss C. A evolução recente da indústria farmacêutica brasileira nos limites da subordinação econômica. Physis. 2018;28(1):1-22. https://doi.org/10.1590/s0103-73312018280104
18. Mendes MB. Avaliação da dependência econômica relativa à importação de insumos farmacêuticos ativos para a produção de medicamentos antirretrovirais pelos laboratórios farmacêuticos oficiais do Brasil [monografia]. Rio de Janeiro: Fundação Oswaldo Cruz; 2013[acesso 16 jun 2020]. Disponível em: https://www.arca. fiocruz.br/handle/icict/11129

19. Arrepia DB. Registro de insumos farmacêuticos ativos: impactos e reflexos sobre as indústrias farmoquímica e farmacêutica instaladas no país [dissertação]. Rio de Janeiro: Fundação Oswaldo Cruz; 2013[acesso 16 jun 2020]. Disponível em: https://www.arca.fiocruz.br/handle/ icict/11628

20. Costa JCS, Pagotto MC, Casas CNPR, Vargas MA, Barros JC, Bermudez JAZ. Avaliação do setor produtivo farmacoquímico no Brasil: capacitação tecnológica e produtiva. Rev Eletronica Comun Inf Inov Saude. 2014;8(4):443-630. https://doi.org/10.3395/reciis.v8i4.432

21. Elias CO, Cunha MF. Avaliação de empresas farmacoquímicas: um estudo de caso goiano sobre percepção de valor. Rev Adm UEG. 2015;6(2):60-71.

22. Agência Nacional de Vigilância Sanitária - Anvisa. Relatório do exercício da gestão 2014. Brasília: Agência Nacional de Vigilância Sanitária; 2015[acesso 4 maio 2019]. Disponível: http://portal.anvisa.gov.br/documents/281258/308532/ Relat\%25C3\%25B3rio\%2Bde\%2BGest\%25C3\%25A30\%2B2014. pdf/9cdb3b74-43f4-435c-92d1-221bfe003101

23. Agência Nacional de Vigilância Sanitária - Anvisa. Relatório do exercício da gestão 2015. Brasília: Agência Nacional de Vigilância Sanitária; 2016[acesso 4 maio 2019]. Disponível: http://portal.anvisa.gov.br/ documents/33776/2941986/Relat\%C3\%B3rio+Gest\%C3\%A30++Exerc\%C3\%ADcio+2015/3f68f524-6619-4ad1-9f0b1d93bb52d9eb

24. Agência Nacional de Vigilância Sanitária - Anvisa. Instrução normativa $N^{\circ} 3$, de 3 de junho de 2013. Dispõe sobre os prazos e o cronograma para a segunda etapa da implantação do registro de insumos farmacêuticos ativos (IFA), definido na resolução da diretoria colegiada $N^{\circ} 57$, de 17 de novembro de 2009, ao quais as empresas estabelecidas no país que exerçam as atividades de fabricar ou importar insumos farmacêuticos ativos e os medicamentos e seus intermediários que os contenham devem ajustar-se. Diário Oficial União. 4 jun 2013.

25. Revista Analytica Online. Indústria farmacêutica segue crescendo em ritmo acelerado. Interfarma Noticias. 24 abr 2020[acesso 16 jun 2020]. Disponível em: https://www.interfarma.org.br/noticias/2219

26. Agência Nacional de Vigilância Sanitária - Anvisa. Relatório de atividades 2018. Brasília: Agência Nacional de Vigilância Sanitária; 2019[acesso 16 jun 2020]. Disponível em: http: / / portal.anvisa.gov.br/documents/281258/2941545/ Relat\%C3\%B3rio+de+Gest\%C3\%A3o+Anvisa+2018/08b ada09-d3a3-47b7-80fb-ebe08f7fae3 
27. Agência Nacional de Vigilância Sanitária - Anvisa. Relatório de atividades 2019. Brasília: Agência Nacional de Vigilância Sanitária; 2020[acesso 16 jun 2020]. Disponível em: http://portal.anvisa.gov.br/ documents/281258/2941545/Relatorio+de+Gestao+Anvisa+2 019/9a19aaa7-96ae-42fd-93d3-9d9c065271ee

28. Agência Nacional de Vigilância Sanitária - Anvisa. Consulta pública № 688, de 12 agosto de 2019. Critérios para certificação de boas práticas de fabricação para estabelecimentos internacionais fabricantes de insumos farmacêuticos ativos. Diário Oficial da União. 15 ago 2019.

29. Agência Nacional de Vigilância Sanitária - Anvisa. Instrução normativa $N^{\circ} 35$, de 21 de agosto de 2019. Dispõe sobre as boas práticas de fabricação complementares a medicamentos estéreis. Diário Oficial União. 21 ago 2019.

30. Massa KHC, Antunes JLF, Lebrão ML, Duarte YAO, Chiavegatto Filho ADP. Fatores associados ao uso de antihipertensivos em idosos. Rev Saude Publica. 2016;50:1-11. https://doi.org/10.1590/s1518-8787.2016050006458

31. Agência Nacional de Vigilância Sanitária - Anvisa. Anuário estatístico. medicamento para o coração está entre os mais vendidos. Brasília: Agência Nacional de Vigilância Sanitária; 2017[acesso 17 jun 2020]. Disponível em: http://portal.anvisa.gov.br/noticias/-/ asset_publisher/FXrpx9qY7FbU/content/medicamentopara-o-coracao-esta-entre-os-mais-vendidos/219201/pop_ up?inheritRedirect=false\&redirect=http\%3A\%2F\%2Fportal. anvisa.gov.br\%2Fnoticias\%3Fp_p_id\%3D101_INSTANCE_ FXrpx9qY7FbU\%26p_p_lifecycle\%3D0\%26p_p_state\%3Dpop_ up\%26p_p_mode\%3Dview\%26p_r_p_564233524_ tag\%3Danu\%25C3\%25A1rio\%2Bestat\%25C3\%25ADstico

32. Secretaria de Salud del Atlántico. Boletín de información de medicamentos del Atlántico. Barranquila: Secretaria de Salud del Atlántico; 2018[acesso 4 abr 2019]. Disponível em: http://www.atlantico.gov.co/images/stories/salud/ farmaco_vigilancia/BIMA_V6_2_20 18.pdf

33. Agência Nacional de Vigilância Sanitária - Anvisa. Resolução RDC N 283, de 17 de maio de 2019. Dispõe sobre investigação, controle e eliminação de nitrosaminas potencialmente carcinogênicas em antagonistas de receptor de angiotensina II. Diário Oficial União. 25 maio 2019.

34. Agência Nacional de Vigilância Sanitária - Anvisa. Anvisa recomenda controle de nitrosaminas por parte dos fabricantes de medicamentos. Brasília: Agência Nacional de Vigilância Sanitária; 2020[acesso 18 jun 2020]. Disponível em: http://portal.anvisa.gov.br/ documents/2857848/5680794/Nota+informativa++Nitrosaminas.pdf/fb31c36a-d205-4613-bef9-668eb7f19538

35. Maranhão MVM, Gomes EA, Carvalho PED. Epilepsia y anestesia. Rev Bras Anestesiol. 2011;61(2):242-54. https://doi.org/10.1590/S0034-70942011000200013

36. Geyer ARC, Sousa VD, Silveira D. Quality of medicines: deficiencies found by brazilian health regulatory agency (Anvisa) on good manufacturing practices international inspections. PLoS One. 2018;13(8):1-17. https://doi.org/10.1371/journal.pone.0202084

37. Braga SL. Análise crítica do abastecimento de insumos farmacêuticos importados sob vigilância sanitária [dissertação]. Niterói: Universidade Federal Fluminense; 2017[acesso 16 jun 2020]. Disponível: https://app.uff.br/ riuff/bitstream/1/5967/1/STEF\%C3\%82NIA\%20LEIRIAS\%20 BRAGA.pdf

38. Agência Nacional de Vigilância Sanitária - Anvisa. Instrução normativa $\mathrm{N}^{\circ} 15$, de 17 de novembro de 2009. Dispõe sobre os prazos, o cronograma e as priorizações para a primeira etapa da implantação do registro de insumos farmacêuticos ativos (IFA), definido na resolução da diretoria colegiada $N^{\circ} 57$, de 17 de novembro de 2009, ao qual as empresas estabelecidas no país que exerçam as atividades de fabricar ou importar insumos farmacêuticos ativos devem ajustar-se. Diário Oficial União. 18 nov 2009.

39. Agência Nacional de Vigilância Sanitária - Anvisa. Resolução RDC N 53, de 4 de dezembro de 2015. Estabelece parâmetros para a notificação, identificação e qualificação de produtos de degradação em medicamentos com substâncias ativas sintéticas e semissintéticas, classificados como novos, genéricos e similares, e dá outras providências. Diário Oficial União. 8 dez 2015.

40. Agência Nacional de Vigilância Sanitária - Anvisa. Guia para obtenção do perfil de degradação, e identificação e qualificação de produtos de degradação em medicamentos. Brasília: Agência Nacional de Vigilância Sanitária; 2015[acesso 30 jul 2020]. Disponível em: http://portal.anvisa.gov.br/documents/10181/2738062/ Perfil+e+produtos+de+degrada\%C3\%A7\%C3\%A30+em+ medicamentos.pdf/c18a4857-9a5c4292-a1bf-07af6cad6902?version $=1.0$

41. Agência Nacional de Vigilância Sanitária - Anvisa. Resolução RDC № 171, de 22 de agosto de 2017. Revisa a aplicabilidade da resolução da diretoria colegiada $N^{\circ} 53$, de 4 de dezembro de 2015, para alterações pós-registro e os prazos desta resolução para produtos já registrados. Diário Oficial União. 24 ago 2017[acesso 2020 jul 28]. Disponível em: http://www.in.gov.br/materia//asset_publisher/ KujrwOTZC2Mb/content/id/19254973/do1-2017-08-24resolucao-rdc-n-171-de-22-de-agosto-de-2017-19254925

42. Galetta A, Schawarz C. Desarollo y validación de metología analítica para la cuantificación simultânea de NDMA y NDEA em compuestos sartanes. Montevideo: Megalab; 2019[acesso 18 jun 2020]. Disponível em: https://d11. com.uy/web/megalabs/plantilla-modelo-01/wp-content/ uploads/2019/10/Validaci\%C3\%B3n-NDMA-y-NDEAAGENCIA.pdf

43. Sociedade Brasileira de Hipertensão - SBH. Esclarecimento quanto a presença de impurezas em medicamentos para hipertensão arterial. Notícias. 1 ago 2019[acesso 18 jun 2020]. Disponível em: https://www.sbh.org.br/arquivos/ noticias/esclarecimento-quanto-a-presenca-de-impurezasem-medicamentos-para-hipertensao-arterial/ 
44. Brasil. Lei $\mathrm{N}^{\circ} 6.437$, de 20 de agosto de 1977 . Configura infrações à legislação sanitária federal, estabelece as sanções respectivas, e dá outras providências. Diário Oficial União. 21 ago 1977.

45. Agência Nacional de Vigilância Sanitária - Anvisa. Medicamentos. Brasília: Agência Nacional de Vigilância Sanitária; 2019[acesso 22 abr 2019]. Disponível em: http://portal.anvisa.gov.br/resultado-de-busca?p_p_ id=101\&p_p_lifecycle=0\&p_p_state=maximized\&p_p_ mode=view\&p_P_col_id=column-1\&p_P_col_count=1\&_101_ struts_action=\%2Fasset_publisher\%2Fview_content\&_101_
assetEntryld=284126\&_101_type=content\&_101_ groupld=33864\&_101_urlTitle=conheca-a-fiscalizacaomedidas-sanitarias\&inheritRedirect=true

46. Agência Nacional de Vigilância Sanitária - Anvisa. Consulta pública $\mathrm{N}^{\circ} 689$, de 12 agosto de 2019. Proposta de diretrizes de qualificação de fornecedores relacionados ao regulamento técnico de boas práticas de distribuição e fracionamento de insumos farmacêuticos, aprovado pela resolução da diretoria colegiada $\mathrm{N}^{\circ} 204$, de 14 de novembro de 2006. Diário Oficial União. 13 ago 2019.

\section{Agradecimentos}

À Universidade Federal de São João del-Rei (UFSJ), em Divinópolis, Minas Gerais, Brasil, pela estrutura disponibilizada, e à CAPES, pelo apoio financeiro (Código 001) concedido ao programa de Pós-Graduação em Ciências Farmacêuticas da UFSJ.

\section{Financiamento}

O presente trabalho foi realizado com apoio da Coordenação de Aperfeiçoamento de Pessoal de Nível Superior - Brasil (CAPES) - Código de Financiamento 001.

\section{Contribuição dos Autores}

Pinto NN, Resende KA - Aquisição, análise, interpretação dos dados e redação do trabalho. Couto RO - Concepção, planejamento (desenho do estudo) e redação do trabalho. Todos os autores aprovaram a versão final do trabalho.

\section{Conflito de Interesse}

Os autores informam não haver qualquer potencial conflito de interesse com pares e instituições, políticos ou financeiros deste estudo.

Licença CC BY-NC atribuição não comercial. Com essa licença é permitido acessar, baixar (download), copiar, imprimir, compartilhar, reutilizar e distribuir os artigos, desde que para uso não comercial e com a citação da fonte, conferindo os devidos créditos de autoria e menção à Visa em Debate. Nesses casos, nenhuma permissão é necessária por parte dos autores ou dos editores. 